\title{
How to defeat male pattern alopecia in a trompeur de femmes, who loves to abuse of libido boosters?
}

\section{Lorenzo Martini}

\author{
Department of Histology and Embryology, University of Siena, Via A. Moro 2, 53100 Siena, Italy
}

Corresponding author: Lorenzo Martini, M.Sc., E-mail: martinil163@libero.it

Sir,

No particular expertise is required to recognize the alopecia androgenetica in male [1], for the recession of the hair line, loss of hair from the crown and the bald pate are more than familiar. In the affected areas the hairs become steadily shorter and finer and finally cosmeticalally useless.

Almost a third of the follicles may disappear at all and the reduction in the lenght of the growing periods reflected in the increased ratio of telogen to anagen in samples of plucked hair.

Alopecia androgenetica is commonly inherited, as an autosomal dominant trait, but always it manifests only in presence of male hormons.

Eunuchs retain their scalp hair even when they have a family history of baldness, unless they are treated with testosterone [2].

Though a correlation with hairiness of the chest has been suggested [1], baldness does not seem to be associated with other indices of masculinity, such as sebum secretion, muscle size and body hai in general [3].

It is suggestive to notice that bald scalp has a greater capacity to convert $5 \alpha$ dehydrotestosterone than non-bald scalp [4], anyway the key to understand the phenomenon of baldness lies in the field of steroid metabolism, even if hypothesis of administering female hormons to men suffering from male pattern alopecia is not plausible.

Manifold trials with 5 alpha reductase inhibitors have been proposed even most recently (it is supervacaneous to stress that the route of administration should be the topical one), for instance:

Zinc hydrosoluble salts [5]

Riboflavin (vitamin B2) [6]

Azelaic acid

$\beta$-sitosterol (and many other phytosterols as well)

Polyphenols [7]

Alizarin (from Rubia tinctoria)

Curcumin

Green tea catechins, including (-)-epicatechin-3gallate, and (-)-epigallo-catechin-3-gallate (EGCG) [8]

Valoneic acid dilactone and gallagyldilactone are two hydrolysable tannin polyphenols isolated from the heartwood of Shorea laeviforia [9] and oaks species such as the North American white oak (Quercus alba) and European red oak (Quercus robur) are inhibitory [10].

\section{Angelica koreana}

Garden Balsam or Rose Balsam (Impatiens balsamina) Pollen of Turnip, turnip rape, fast plants, field mustard, or turnip mustard (Brassica rapa)

Dodder (Cuscuta reflexa)

Euphorbia jolkinii

Lingzhi mushroom or Reishi mushroom (Ganoderma lucidum)

Ganoderic acid or Ganoderol B are thought to be the compounds in the mushroom that are specifically active.

Chinese Knotweed (Polygonum multiflorum), contains resveratrol-like Stilbenoids.

Black Pepper leaf extract (Piper nigrum)

Red Stinkwood (Pygeum africanum)

Saw Palmetto (Serenoa repens, active substance possibly lauric acid [11].

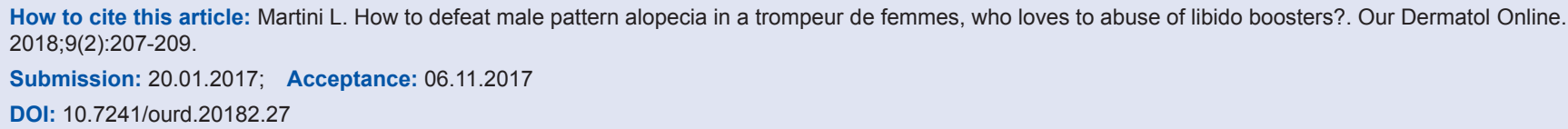


The berries of saw palmetto (Serenoa repens), a small palm native to the south east United States, possess a dual 5 a-reductase inhibition activity, due to their high content of phytosterols: $\beta$-sitosterol, stigmasterol, lupeol, lupenone, and cycloartenol. Permixon ${ }^{\circledR}$ was launched in Europe in 1984 but has no FDA approval. The lipido-sterol extract markedly inhibits both the human isoenzymes. Type 1 isoenzyme is noncompetitively $(\mathrm{Ki}=7.2 \mu \mathrm{g} / \mathrm{mL}$ ) and type 2 isoenzyme uncompetitively $(\mathrm{Ki}=4.9 \mu \mathrm{g} / \mathrm{mL})$ inhibited.

Pine (Pinus sp. resin, active substance abietic acid) Japanese hedge parsley (Torilis japonica)

Eastern Arborvitae, Northern Whitecedar (Thuja occidentalis)

Spore of Japanese climbing fern (Lygodium japonicum)

Certain unsaturated fatty acids keeping on account that the relative inhibitory potencies are, in decreasing order: Gamma-Linolenic acid, alpha-linolenic acid, linoleic acid, palmitoleic acid, oleic acid, and myristoleic acid [12].

Medium chain fatty acids such as those found in coconut and the kernel of many palm fruits.

We have recruited a man (49 y. old) who likes to be defined a "latin lover" as he has been always a trompeur de femmes since he was a pre-pubertal child and observed the very first manifestations of alopecia androgenetica when he was $21 \mathrm{y}$. old.

He uses all the types of possible aphrodisiacs to induce in himself an increasing appetite for sex intercourses (yohimbine, damiana turnera extract, sildenafil and tadalafil compounds at massive dosages that may permit him to have 4 or more sexual encounters for day) with diverse women.

He is accustomed too to spread onto his poor hair scalp hairdressing gels and brilliantines, that are considered [13] exceptional inducers of baldness in man.

We prayed him to massage onto his scalp affected by baldness twice a day a cosmetic containing four 5 alpha reductase inhibitors, dispersed in the Macassar oil (an ancient formula by Dr. Rowland), that foresees the presence of essential oils of cloves, cynnamon, rose églantine and alkanna concrete in olive oil.

The 5 alpha reductase inhibitors were:

- betasitosterol (1\%)

- green tea catechins (2\%)

(c) Our Dermatol Online 2.2018
- black pepper oil (piper cubeba seed oil) (1.5\%)

- curcumin $(0.5 \%)$.

The experimentations lasted three months, and I have always wanted to be sure that he used the remedy We gave him everyday.

Amongst the manifold ways to clinically state the degree of hair re-growth, We have choosen the histological $H \& E$ test, efefctuated by the aids of a microscope.

It is known that Hematoxylin dyes the cellular nuclei blue, while eosin dyes the non-nuclear cells and structures pink/orange, such as cytoplasm and collagen. Combined, these dyes assist in recognizing the basal cells or germ layer: Cells rest on the dermis; blue nuclei are visible and this is where mitosis occurs and cells divide.

This clearily represents the phenomenon of the restoring of matrix of the hair follicle.

It is mandatory to effectuate a previous histological test, and to repeat it picking some hair from the scalp every 2 weeks for all the period of the experimentation.

The very first microscopic evaluation on hair revealed that, due to testosterone, numerous hair follicles were in the telogen phase as they showed characteristics of telogen follicles i.e. being short and hollow, presence of necrosis, more destroyed follicles, follicle shrinkage means diameter decreases and not deeper. Just after the first week the number of follicles in anagen phase was considerably increased and the number of follicles in telogen phase was decreased because surely the cosmetic item has inhibited the action of testosterone on hair follicles. The increase in the number of hair follicles was also noted. At the evaluation of the second week follicles showed characteristics of anagen follicles i.e. longer follicle hair and follicles were dense, less cell necrosis, and present deeper.

It can be asserted that the number of follicles in hair growth phase increased with duration of treatment. The hair follicle density and anagen/telogen ratio (A/T ratio) was calculated and plotted in the following Table 1.

\section{RESULTS}

It is evident that after only two weeks of treatment one may assert that hair restoration is almost complete, as far as the anagen/telogen ratio is concerned. 
www.odermatol.com

Table I: Values scored after one and two weeks of experimentations by $\mathrm{H}$ and $\mathrm{E}$ test on hair picked from hair scalp of the volunteer

\begin{tabular}{lcc}
\hline $\begin{array}{l}\text { Day of the performing } \\
\text { of } \mathbf{H} \text { and } \mathbf{E} \text { tests }\end{array}$ & $\begin{array}{c}\text { Hair follicular } \\
\text { density }(\mathbf{n o .} / \mathbf{m m})\end{array}$ & $\begin{array}{c}\text { Anagen to } \\
\text { telogen }\end{array}$ \\
\hline First evaluation (at day 0$)$ & $1.5 \pm 0.90$ & $1: 3.16$ \\
After 1 week $\left(7^{\text {th }}\right.$ day) & $3.3 \pm 0.77^{\star}$ & $1.22: 1$ \\
After 2 weeks $\left(14^{\text {th }}\right.$ day) & $2.75 \pm 0.75^{\star *}$ & $1.12: 1$ \\
\hline
\end{tabular}

The Savin scale is a objective method of investigation on the hair re-growth (it is used generically for testing the hair re-growth women) but I attempted to use it even for my volunteer.

The scale ranges from degree III (complete baldness of the pate) to II-2, II-1, I-4, I-3, I-2 and finally I-1 (complete restoration of hair scalp).

We could affirm that after two weeks the degree II-l is reached and after two months (8 weeks of treatment) degree I-2 is achieved completely.

As far as the blood testosterone, the first measurements reveal an amount of $1103 \mathrm{ng} / \mathrm{dl}$ meanwhile at the end of the experimentations, this value decreased to $256 \mathrm{ng} / \mathrm{dl}$

\section{REFERENCES}

1. Baccaredda-Boy A, Moretti G, Frey JR. Biopathology of pattern alopecia, 1967, Ed. Karger, Bern
2. Hamilton J. Am J Anat. 1942;71:451.

3. Burton JL, Ben Halim MM, Meyrick G, Jeans WD, Murphy D. Br J of Dermatol. 1979;100:567.

4. Binghma KD, Shaw DA. J Endocrinol. 1973;57:11.

5. Stamatiadis D, Bulteau-Portois MC, Mowszowicz I. Inhibition of 5 alpha-reductase activity in human skin by zinc and azelaic acid. $\mathrm{Br}$ J Dermatol. 1988;19:627-32.

6. Osamu N, Masashi Y, Sumio K, Masakuni O, Masanobu K. Riboflavin, a testosterone 5-alpha-reductase inhibitor. J Antibiot. 1990;43:1615-6.

7. Hiipakka RA, Zhang HZ, Dai W, Dai Q, Liao S. Structure-activity relationships for inhibition of human 5alpha-reductases by polyphenols. Bioch Pharmacol. 2002;63:1165-76.

8. Liao S, Lin J, Dang MT, Zhang H, Kao YH, Fukuchi J, et al. Growth suppression of hamster flank organs by topical application of catechins, alizarin, curcumin, and myristoleic acid". Arch Dermatol Res. 2001;293:200-5.

9. Yoshio H, Ryuichiro K, Kokki S. 5A-Reductase inhibitory tanninrelated compounds isolated from Shorea laeviforia. J Wood Scien. 1995;49:339-43.

10. Pirjo M, Heikki S, Lasse L, Juhani K, Terttu V. Analysis of oak tannins by liquid chromatography-electrospray ionisation mass spectrometry. J Chromatograp A. 2000;891:75-83.

11. Edgar AD, Levin R, Constantinou CE, Denis L. A critical review of the pharmacology of the plant extract of Pygeum africanum in the treatment of LUTS. Neurourol Urodynam. 2007;26:458-63.

12. Liu J, Shimizu K, Kondo R. Anti-androgenic activity of fatty acids. Chem Biodivers. 2009;6:503-12.

13. Butler H. Poucher's Perfumes, Cosmetics and Soaps; 2013, Ed: Springer Science \& Business Media.

Copyright by Lorenzo Martini. This is an open-access article distributed under the terms of the Creative Commons Attribution License, which permits unrestricted use, distribution, and reproduction in any medium, provided the original author and source are credited.

Source of Support: Nil, Conflict of Interest: None declared. 